
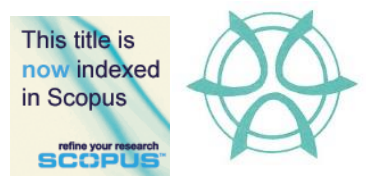

PLANNING MALAYSIA:

Journal of the Malaysian Institute of Planners

VOLUME 15 ISSUE 1 (2017), Page 179 - 190

\title{
CONTENT ANALYSIS OF THE EXISTENCE OF BIOMIMICRY LIFE'S PRINCIPLES IN GREEN BUILDING INDEX MALAYSIA
}

\author{
Noor Aziah Mohd Ariffin'1, \& Salwa Farag Gad ${ }^{2}$ \\ ${ }^{1,2}$ Kulliyyah of Architecture and Environmental Design \\ INTERNATIONAL ISLAMIC UNIVERSITY MALAYSIA
}

\begin{abstract}
Concerns about climate change and global warming have led many countries to initiate energy rating systems in the planning and development of the built environment. Although useful and novel, this paper contends that these ratings are only remedying and alleviating whatever negative impacts that development creates. Energy ratings are seemingly lacking in attempts to integrate and enhance the physical development of the natural environment. Instead, biomimicry is a discipline that explores nature and tries to understand its bio-integration for the establishment of sustainable products, processes and systems. This paper postulates that with the integration of Biomimicry - Life's Principles (BLP) into the Green Building Index (GBI) Malaysia, a higher level of environmental sustainability could be achieved. This paper attempted to explore the presence and the extent of the presence of BLP in the existing GBI utilizing the content analysis method. This article concludes that although the presence of BLP in the GBI is high, the extent of the presence is low. The paper also recommends the areas of concern that could be improved within the GBI for a more effective rating system.
\end{abstract}

Keyword: Green Building Index (GBI); Biomimicry - Life's Principles (BLP); content analysis; presence; extent of presence

Date Received: $30^{\text {th }}$ April 2016

Date of Acceptance: $30^{\text {th }}$ October 2016 
Noor Aziah Mohd Ariffin, \& Salwa Farag Gad

Content Analysis of The Existence of Biomimicry Life's Principles in Green Building Index Malaysia

\section{INTRODUCTION}

The primary aim of this paper is to explore the existence of BLP within the GBI Malaysia. Thus, the study was conceptualised based on three objectives: The first is to explore the meaning and concept of biomimicry in the development of the built environment. Secondly, is to analyse the presence of biomimicry principles in the current energy rating tools and finally, is to analyse the extent of that presence or usage of BLP in the GBI system.

\section{What is Biomimicry?}

The term biomimicry comes from the Greek words bios, meaning life, and mimesis, which mean to imitate (Baumeister, 2012). This concept emerged in 1982 and was made famous by Janine Benyus in her book 'Biomimicry: Innovation Inspired by Nature' in 1997. Benyus (1997) defines biomimicry as the "new science that studies nature's models and then imitates or takes inspiration from these designs and processes to solve human problems". Biomimicry is a scientific approach that examines nature's lessons and methods, which are applied to the processes and designs to solve human problems. It seeks sustainable solutions by imitating nature's patterns and strategies (Zanowick, 2011). According to Gamage \& Hyde (2012), biomimicry could be called 'strong ecological design' because it advocates using the same materials and processes applied by nature closely. Reap (2009) used three verbs to define biomimicry: 'study, imitate and solve'. Reap (2009) studies the living systems with the intent of imitating it to solve technical problems. Additionally, a final evaluation was required to ensure that the product or design commensurate with the natural principles.

Biomimicry has achieved some innovative and efficient technologies in materials and product, and has resulted in numerous innovations in fields such as transportation, material science and medicine. It is also gaining recognition in the design professions such as architecture (Gamage \& Hyde, 2012). Designers and architects are becoming more interested and aware of how much nature can offer to improve the way the systems function. El Ahmar et. al., (2013) among others, contended that biomimicry is a growing area of research in the field of architecture and engineering. However, it is still unrealized, largely in architecture as demonstrated by the small number of built case studies (El-Zeiny, 2012; Klein, 2009; McGovern, 2009). The paper suggests that biomimicry should be considered as an approach to increase the sustainability of a building project. The mimicking of general ecosystem principles should be integrated into the design at the earliest stage and utilised as an evaluative tool all over the design process (Zari, 2015).

\section{Biomimicry Design Lens}

The 'Biomimicry Design Lens' (Figure 1) is a guide that helps in understanding how biomimicry can be applied to any discipline or design scale. The Lens includes the Biomimicry - Life's Principles (BLP), and Biomimicry Thinking 
PLANNING MALAYSIA

Journal of the Malaysia Institute of Planners (2017)

(Biomimicry 3.8, 2013). The Biomimicry - Life's Principles (BLP) represents 'Nature's strategy for sustainability' and they provide a lens to observe design strategies (Zanowick, 2011). According to Biomimicry 3.8 (2013), these principles also signify the central patterns found among the species living on Earth. The Design Lens or framework demonstrated six (6) main principles and twenty (20) sub-principles. The principles are all equally weighted, and they are (in no particular order): Adapt to Changing Conditions; Be Locally Attuned \& Responsive; Use Life-Friendly Chemistry; Be Resource Efficient; Integrate Development with Growth and Evolve to Survive. The BLP design lens was used as a guide in assessing the primary aim in this paper (Figure 1).

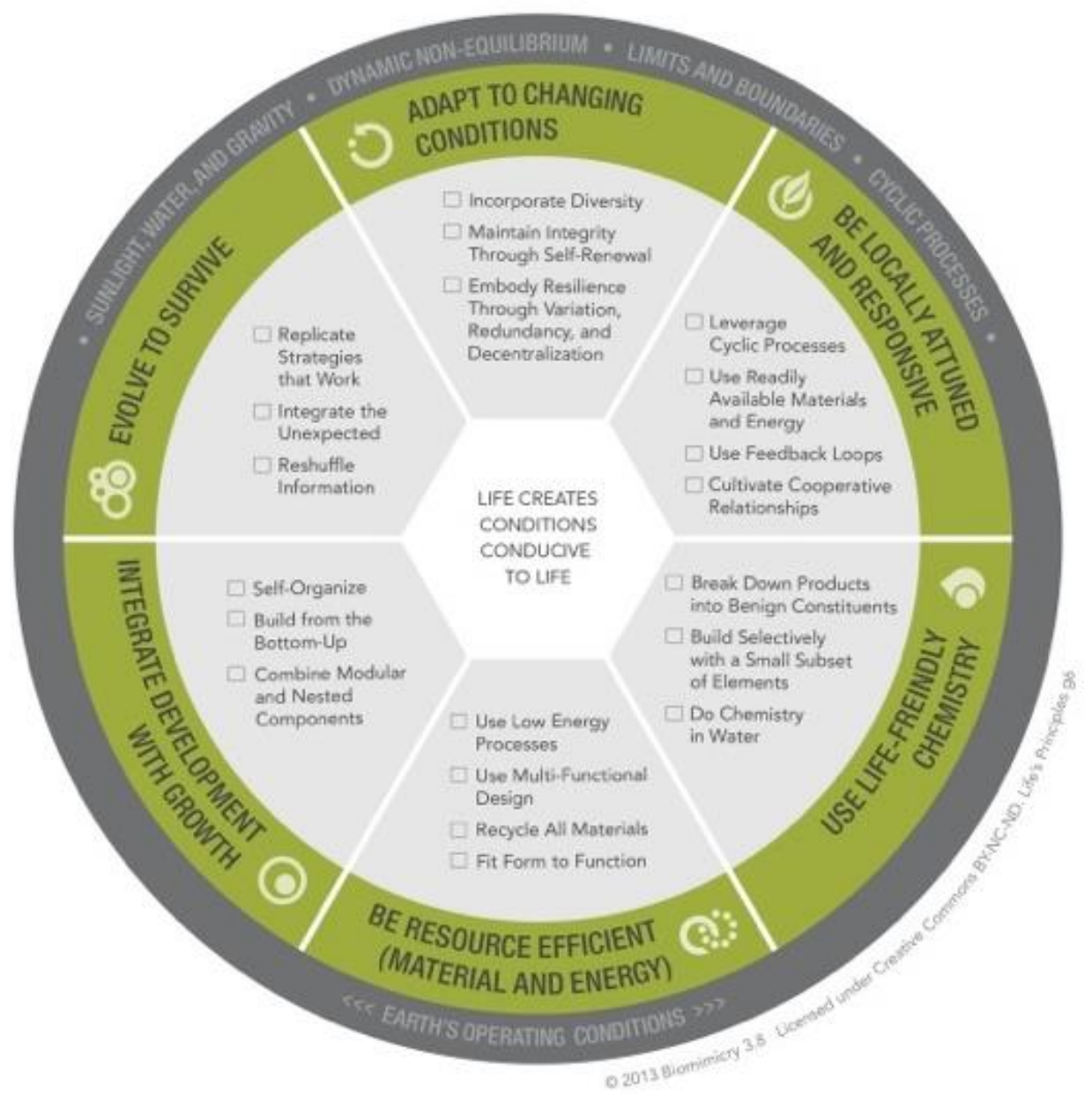

Figure 1 The Biomimicry Design Lens Source: http://biomimicry.net/ 
Noor Aziah Mohd Ariffin, \& Salwa Farag Gad

Content Analysis of The Existence of Biomimicry Life's Principles in Green Building Index Malaysia

\section{Green Building and Green Building Rating Systems}

The main motivation behind the green building movement is the sustainable development paradigm (Kibert, 2012). Green building is an outcome of applying sustainable construction approaches to provide a responsible built environment. The term 'green building' refers to the actual structures' quality and characteristics that are provided using sustainable construction principles and methodologies (Kibert, 2012). At present, Green building movement grows rapidly and it is supported by many government and nongovernment organisations. This movement becomes popular among professionals and authorities to create a balance between the building and its surrounding environment. The goals are to lower the buildings' adverse impacts on the environment during the life cycle of the building, which can be achieved through better design, siting, construction, operation, maintenance and demolition. A building is defined as green when it has undergone an evaluation process. The evaluations are to verify that a building follows the strict requirements of the green building rating systems to provide detailed assessments (Kibert, 2012). As a result, these systems can be called assessment building systems, or building rating tools or systems such as the Leadership in Energy and Environmental Design (LEED) (US, 1998) and Green Building Index (GBI) (Malaysia, 2009).

GBI Malaysia is made up of six Parts: Energy Efficiency, Indoor Air Quality, Sustainable Site Planning and Management, Materials and Resources, Water Efficiency and Innovation. Under each of these Parts, there are several criteria according to which the building will be evaluated. In the beginning, two GBI rating tools were developed: the Non-Residential and the Residential rating tools. After that, several more tools were developed. Recently, there are around $11 \mathrm{GBI}$ rating tools. Each of these rating tools has its own point allocation, where each tool places its emphasis on GBI criteria that are different from other tools. One of these tools is the Non-Residential New Construction (NRNC), which is the focus of this research.

\section{Green Building and Nature}

As stated before, the natural systems have many solutions for the current problems that people are facing nowadays. Most of green building's definition states that ecology and ecological principles are important for the designing of green buildings. However, some critics claim that ecological or natural-based principles do not exist in a coherent manner in the green buildings (Gamage \& Hyde, 2012). Some other critics suggest that most green building designs operate as a collection of eco-technologies such as photovoltaic panels and eco materials (Yeang, 2006). This illustrates a lack of knowledge in understanding the significance of holistic integration (Gamage \& Hyde, 2012). According to Kibert (2012), the progress of high-performance green building requires the ability of the design team to understand and apply ecology and its principles. In other words, buildings should have 'a synergistic relationship' with the natural 
environment surrounding it (Kibert, 2012). Kibert (2012) claims that green building with higher economic and aesthetic value can be produced when there is a use of design approach that is based on the understanding of natural systems and ecosystems' behaviour. In short, green buildings need to go beyond the points and certifications, and they are required to integrate and blend with nature and this cannot be achieved with a simple checklist as used by most rating tools.

\section{METHODOLOGY}

This paper is the beginning of a deeper study and is more exploratory in nature. In order to achieve the stated aim and the subsequent questions, the principle methodology used in this study is utilizing the content analysis method. Analyses were done on the GBI documents to investigate on the presence and on the extent of the application of the biomimicry principles in the existing ratings. The content analysis used not only the exact words but also the meaning or concepts of the BLP that are deemed relevant in the GBI. The findings of the analysis would from a basis for the recommendation of improving the present GBI document wherever relevant.

\section{Content Analysis}

Content analysis is a method of analysing documents, and it helps in testing theoretical issues to improve the understanding of the data (Elo \& Kynga, 2007). There are different levels of content. There is the primary content that is represented by themes and main ideas of the text, and there is a latent content that is represented by the context information. The purpose of content analysis method is to provide new insights, knowledge, a representation of facts and a practical guide to action and also to get a shortened or broad explanation of the phenomenon (Elo \& Kynga, 2007). The processes of content analysis involves coding of raw data, such as visual images, textual material, and illustrations, in accordance with a classification scheme. The coding is a process for organizing content in a way that helps in easily identifying, indexing, or retrieval of the content that is relevant to the research questions. The components of the content could be words, phrases, topics, theories, concepts or other features.

Content analysis method is used with either qualitative or quantitative data by either deductive or inductive processes and consists of three phases of work: preparation, organizing and reporting. The preparation phase includes deciding on sampling, selecting the unit of analysis and making sense of data. After that, a decision will be made whether to use deductive or inductive approach. If the deductive approach is chosen, a categorization or conceptual matrix will be developed (Elo \& Kynga, 2007). The data are coded for correspondence with the identified categories or concepts. For each deductive category, clear definitions, examples, and coding rules must be provided and arranged in a coding agenda. There are several computer programs that are widely used for content analysis, and one of them is ATLAS.ti. This program works as an assistant in working through the material, writing marginal notes, defining 
Noor Aziah Mohd Ariffin, \& Salwa Farag Gad

Content Analysis of The Existence of Biomimicry Life's Principles in Green Building Index Malaysia

category and codes, underlining, writing comments and others. Also, it is a very helpful tool for handling the text.

The deductive approach was used because the BLP was developed by the Biomimicry Institute (Biomimicry 3.8, 2013). It is divided into six main categories and twenty sub-categories. BLP were coded as the codes/categories and the GBI document was coded for correspondence with the identified codes/categories. The codes definition of BLP document (Biomimicry 3.8, 2013) is shown in Table 1.

Table 1 The Code Definition for BLP

\begin{tabular}{llcc}
\hline \multicolumn{1}{c}{ Document } & Main Principles & Code & $\begin{array}{c}\text { Sub- } \\
\text { principles }\end{array}$ \\
\hline BLP - & Evolve to Survive & C1 & 3 \\
Biomimicry & Be Resource (Material \& Energy) & C2 & 4 \\
Life's Principles & Efficient & C3 & 3 \\
& Adapt to Changing Conditions & C4 & 3 \\
& Integrate Development with Growth & C5 & 4 \\
& Be Locally Attuned and Responsive & C6 & 3 \\
\hline & Use Life- Friendly Chemistry & Total & 20 \\
\hline
\end{tabular}

The codes definition of GBI document (Non-Residential New Construction (NRNC), 2015) is shown in Table 2.

Table 2: The Code Definition for GBI

\begin{tabular}{|c|c|c|c|c|}
\hline Document & Parts & & Code & Criteria \\
\hline GBI, Green & Energy Efficiency & & $\mathrm{EE}$ & 9 \\
\hline \multirow[t]{6}{*}{ Building Index } & Indoor Environmental Quality & & EQ & 15 \\
\hline & $\begin{array}{l}\text { Sustainable Site } \quad \text { Planning } \\
\text { Management }\end{array}$ & $\&$ & SM & 13 \\
\hline & Materials \& Resources & & MR & 7 \\
\hline & Water Efficiency & & WE & 5 \\
\hline & Innovation & & INV & 2 \\
\hline & & & Total & 51 \\
\hline
\end{tabular}

\section{Stages for Conducting Content Analysis}

Stage 1 is the Preparation stage where both documents were analysed and the coding was specified and assigned. The researcher decided to code for sets of words, phrases or themes, which were relevant or related to the specified codes/concepts (pre-defined set of categories). Stage 2 is the Organization stage where the software Atlas.ti was actively used in the coding process. Atlas.ti was helpful in working through the text, underlying, writing comments and applying codes to a highlighted or selected text. These actions were to look for the 
existence of assigned words and concepts according to the codes specified in the GBI document. The codes were then organised into categories, using the Biomimicry Lens as a guide. The outcome of this is shown in Stage 3, the Reporting stage. This stage is the most crucial stage where the results found from Stage 2 were presented in tables and charts for clarity of reporting. In this stage, the BLP Lens was used to illustrate the presence of these principles in the GBI terms.

\section{ANALYSIS \& RESULTS}

Most of the analyses were done in Stage 2: the coding process. Coding of the text was conducted by reading through the documents and manually writing down the occurrences of concepts identified, using Atlas.ti. The GBI rating tool was considered as the document or data analysed according to the existence of the codes (as concepts and not as exact words). The text was coded using ATLAS. $\mathrm{Ti}$ (attaching the code to a text that used the principle) and the results were arranged in a matrix and finally reported in the forms of bar chart and as a summary, the radar chart. The results were reported in terms of the presence and the extent of this presence. Table 3 shows an example of the coding process undertaken.

Table 3 Example of the Coding Process of the Occurrences of the Concepts in the GBI similar to BLP

\begin{tabular}{|c|c|}
\hline \multicolumn{2}{|c|}{ BLP: C 1-1: Replicate Strategies that Work } \\
\hline GBI Criteria & Quotation \\
\hline $\begin{array}{ll}\text { EE1: } & \text { Minimum EE } \\
& \text { Performance }\end{array}$ & "Promote the use of MS 1525." \\
\hline $\begin{array}{l}\text { EQ6: Thermal Comfort: Design } \\
\text { \& Controllability of } \\
\text { Systems }\end{array}$ & $\begin{array}{l}\text { "Design to ASHRAE } 55 \text { standards in conjunction } \\
\text { with the relevant localised parameters as listed in } \\
\text { MS 1525:2007." }\end{array}$ \\
\hline $\begin{array}{l}\text { EQ10: Electric Lighting } \\
\text { Levels }\end{array}$ & $\begin{array}{l}\text { "The ambient lighting level should be designed in } \\
\text { accordance with the illuminance level } \\
\text { recommended in MS1525:2007." }\end{array}$ \\
\hline SM13: Building User Manual & $\begin{array}{l}\text { "To document Green building design features and } \\
\text { strategies for user information and guide to sustain } \\
\text { performance during occupation." }\end{array}$ \\
\hline
\end{tabular}

The coding process was where the texts within the GBI were coded for the presence of the Biomimicry life's principles (BLP) as obtained from Atlas.ti. In addition, the extent of existence was also provided in the form of the percentages of the presence of each main principle in GBI. It is important to note that the coding was for the presence of the concept/principles and not how it was applied. 
Noor Aziah Mohd Ariffin, \& Salwa Farag Gad

Content Analysis of The Existence of Biomimicry Life's Principles in Green Building Index Malaysia

The aim was to find out whether these concept or principles were embodied or employed in the GBI criteria or not.

The next step was to categorise or arrange the quotations from the GBI text (coded text as shown above) into a matrix to look for the presence of the BLP in the GBI. An example of the categorization matrix of the presence of BLP in the Energy Efficiency Part from the GBI is shown in Table 4.

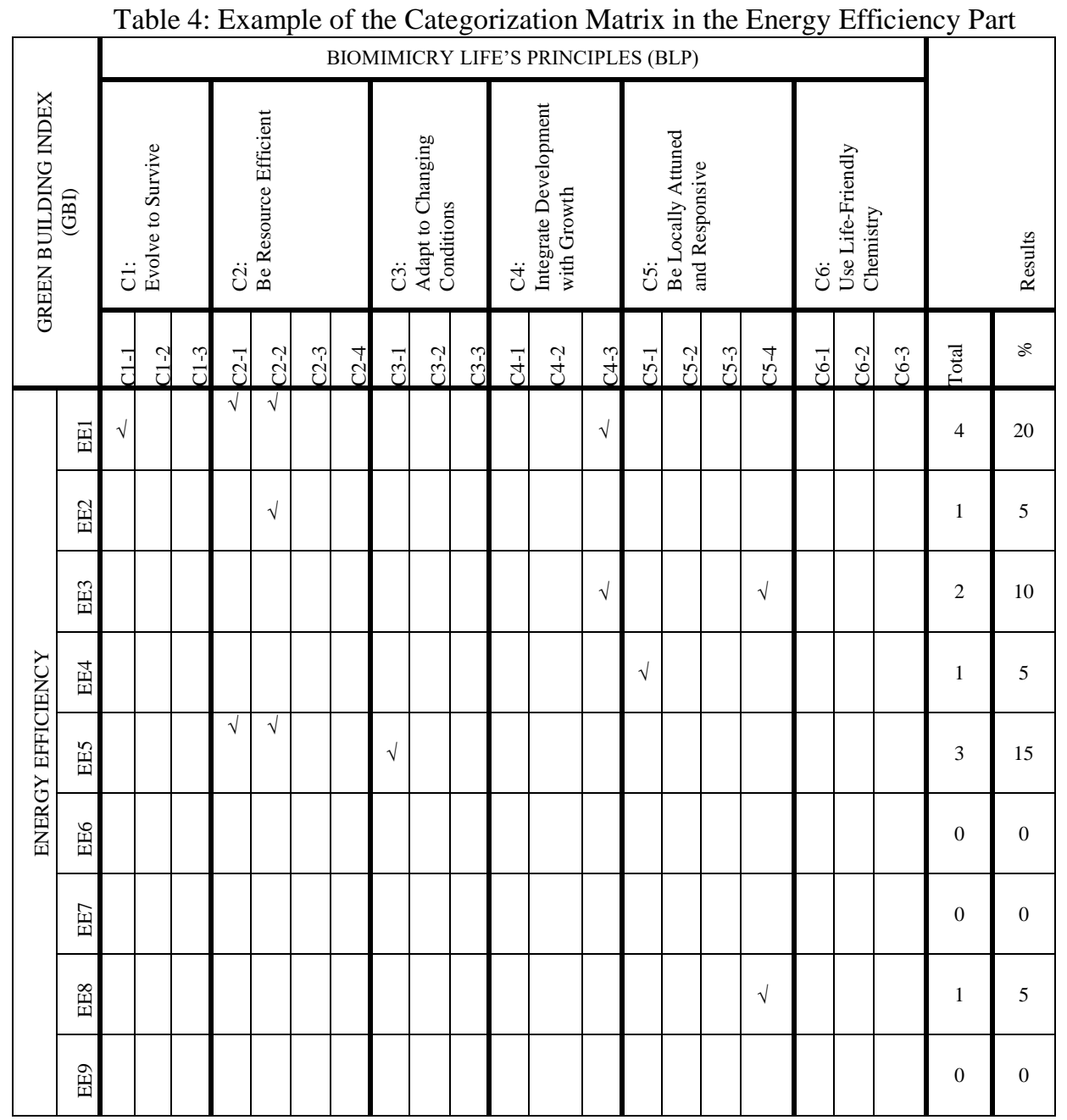

The categorization matrix was conducted for all 6 Parts of the GBI document (refer to Table 2). These were further analysed to present the investigation of the BLP codes in the GBI documents. 
The presence of the BLP was reported at two levels: in GBI as a whole and then in each part of the GBI. On the other hand, the extent of the presence has two dimensions: the extent of the fulfilment of BLP itself and their extent of the presence in GBI. This study takes the stand that all principles must be fulfilled to create conditions conducive to live as seen in the Biomimicry Life's Principles framework or lens. The summary of the findings is reported next.

\section{The Presence of BLP in GBI}

When looking at the GBI as a whole, the level of presence of the BLP is a likely $65 \%$. This result means that much of the contents of the GBI include the themes and concepts as coded and categorised from the BLP. The total number of presences equate to the number of sub-principles found in the whole GBI document. Further analyses showed that 13 BLP sub-principles out of a total of 20 were present but in the different Parts of the GBI. The radar chart in Figure 2 illustrates the summary of the results of the three levels of analyses on the presence of the BLP in the GBI.

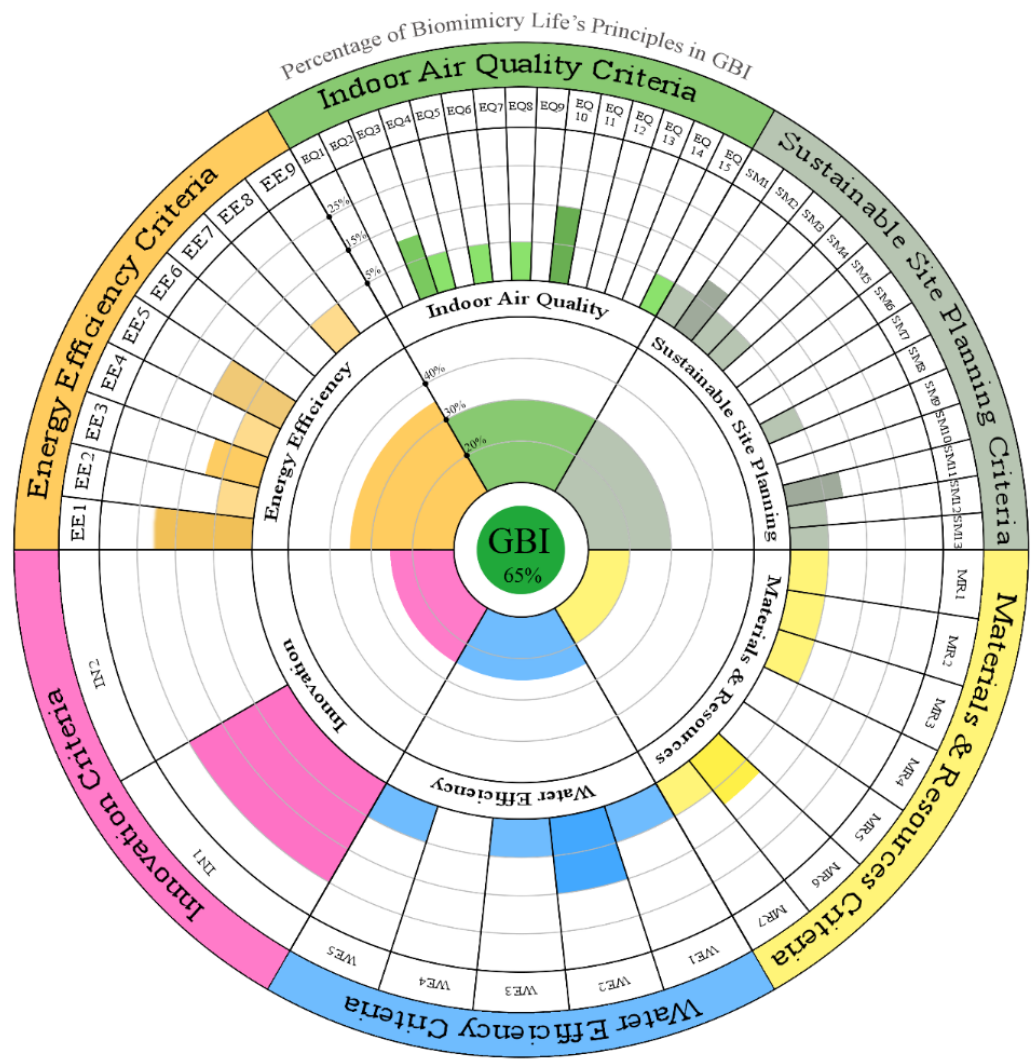

Figure 2 Summary of the Presence of Biomimicry Life Principles in GBI 
Noor Aziah Mohd Ariffin, \& Salwa Farag Gad

Content Analysis of The Existence of Biomimicry Life's Principles in Green Building Index Malaysia

The most outer ring presents the 6 Parts of the GBI (see Table 2). The second ring shows the criteria of each Parts and the third ring shows the levels of occurrence/presence of BLP in each criteria of the GBI. Going inwards, the fourth ring shows the levels of fulfilment or the extent of the presence of the BLP in the GBI. The innermost or smallest ring shows the total and percentage of the presence of BLP in the GBI.

All Parts of the GBI were represented, but not all criteria have the presence of the BLP. For example, in the Innovation (IN) Part, which consisted of only two criteria (IN1 \& IN2), BLP is only found in one criterion. However, the level of the fulfilment of BLP is the highest (25\%) amongst all criteria. Another example is the Indoor Air Quality (IAQ) Part, where nine criteria out of fifteen do not have any BLP presence in them. When going deeper into the inner ring, the result illustrates the magnitude of the presence of BLP in each GBI Part on the whole. Energy Efficiency (EE) Part obtained the highest presence of BLP with $35 \%$. On the other hand, Materials and Resources (M\&R) Part has seven criteria but the lowest number of BLP with only $20 \%$ presence.

\section{The Extent of the Presence of BLP in Parts of GBI}

The definition of the extent of presence here means the level of frequency of the presences of the BLP in the GBI. The frequency was obtained through a categorization matrix where the presence of the BLP sub-principles was ticked against the criteria in the GBI when found. These occurrences may appear several times in some criteria/sub-principle matrix. While in another matrix, it may not appear at all. The results are shown in Figure 3.

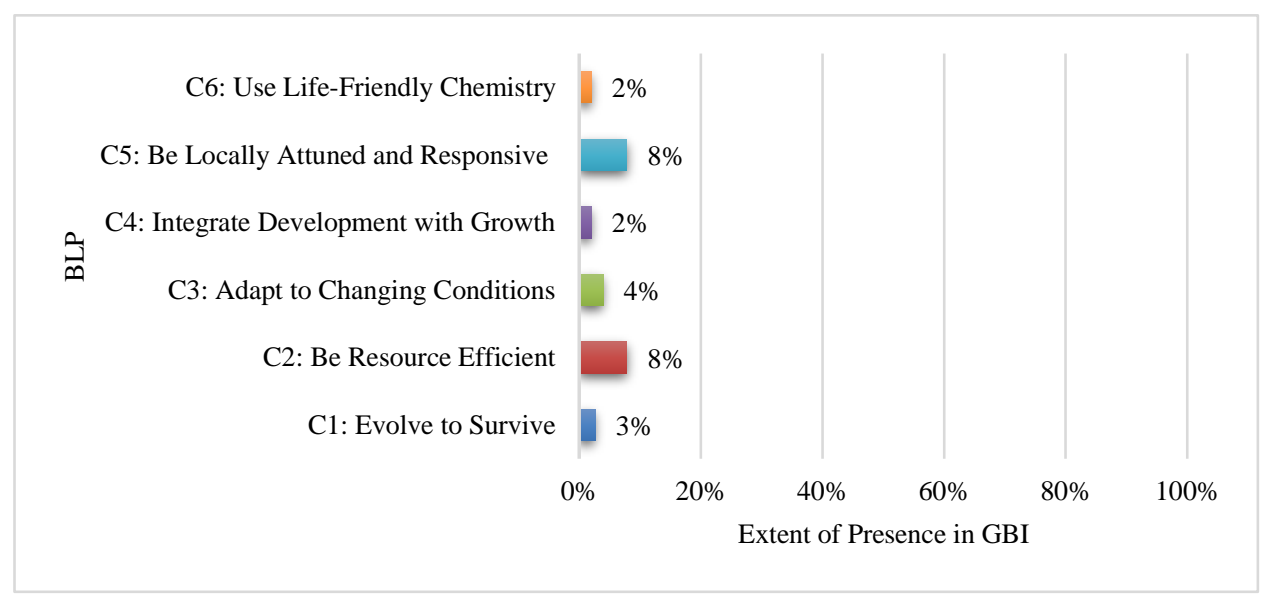

Figure 3 The Extent of Presence of BLP in GBI

The results show the percentage of the extent of the presence of each main principle of BLP in the GBI. Although many of the BLP existed in GBI as a whole $(65 \%)$, the extent (or level of frequency) of the presence is low. The 
PLANNING MALAYSIA

Journal of the Malaysia Institute of Planners (2017)

highest numbers of the frequency of presence $(8 \%)$ in GBI are evident in two principles. They are "Be Locally Attuned and Responsive" and "Be Resource Efficient (Materials and Energy)". The lowest extent of presence is by the "Use Life-Friendly Chemistry" and "Integrate Development with Growth" principle, where the extent is only $2 \%$ in the GBI criteria.

This result would infer that more efforts are required to increase and enhance these principles in the GBI. On average, the total of the extent of the presence of BLP was calculated as $4.7 \%$ in the whole GBI. This finding indicated poor bio-integration of ecological principles into the existing green buildingrating tool.

\section{CONCLUSION}

Green building design and biomimicry are two different evolving approaches to sustainability in the built environment. Green building design aims to achieve the sustainable development goals and principles. On the other hand, biomimicry seeks to study nature's models to solve all problems that humans face nowadays. In other words, biomimicry is based on the natural model while the green building relies on the man-made model. As demonstrated, nature is considered as a perfect paradigm of sustainability and, therefore, using the biomimicry life's principles in green building design could be very beneficial. The synergy between biomimicry and green building design can help in improving and further develop the green building rating tools that are widely used by building's professionals to help them define and produce a sustainable building.

This research uses the Biomimicry Life's Principles (BLP) framework or lens to analyse the GBI Malaysia rating tool. The whole GBI document was examined against the existence of Biomimicry principles in it. This study helped in highlighting the natural principles that exist in GBI and also indicating those that do not exist. Once the missing attributes were found, efforts can be made to enhance the content of the GBI document to achieve a higher level of sustainability. The study explicated the extent of the presence of BLP in GBI, which, in general, is low. The findings inferred a need for more integration of the BLP in the next generation of the GBI rating tool. Future study would be to find out how the missing principles may be included in the existing GBI and how the other existing principles may be enhanced. An improved framework can be developed in which all the criteria are designed based on the natural principles where all criteria are working together to help professionals in producing the building that "create conditions conducive to life".

\section{ACKNOWLEDGEMENTS}

The authors would like to acknowledge the International Islamic University Malaysia, in particular the Faculty of Architecture \& Environmental Design, where this research took place. 
Noor Aziah Mohd Ariffin, \& Salwa Farag Gad

Content Analysis of The Existence of Biomimicry Life's Principles in Green Building Index Malaysia

\section{REFERENCES}

Baumeister, D. (2012). Biomimicry resource handbook, life's principles, and biomimicry spirals. Missoula MT, USA: Biomimicry Group Inc.

Benyus, J. (1997). Biomimicry: innovation inspired by nature. New York, USA: William Morrow \& Company, Inc.

Biomimicry 3.8. (2013). Biomimicry Design Lens: A visual guide. USA.

El Ahmar, S., Fioravanti, A., \& Hanafi, M. (2013). A methodology for computational architectural design based on biological principles. In eCAADe 2013: Computation and Performance - Proceedings of the 31 st International Conference on Education and research in Computer Aided Architectural Design in Europe. Delft: Faculty of Architecture, University of Delft.

El-Zeiny, R. M. A. (2012). Biomimicry as a problem solving methodology in interior architecture. Procedia - Social and Behavioral Sciences, 50, 502-512.

Elo, S., \& Kynga, H. (2007). The qualitative content analysis process. Journal of Advanced Nursing, 62, 107-115.

Gamage, A., \& Hyde, R. (2012). A model based on Biomimicry to enhance ecologically sustainable design. Architectural Science Review, 55(3), 224-235.

Kibert, C. J. (2012). Sustainable Construction: Green Building Design and Delivery (3rd ed.). Canada: John Wiley \& Sons.

Klein, L. (2009). A phenomenological interpretation of Biomimicry and its potential value for sustainable design. (Doctoral dissertation) Kansas State University.

McGovern, J. (2009). Biomimicry: how learning from nature can restore sustainability in architecture. (Master's dissertation) University of Cincinnati.

Non-Residential New Construction (NRNC) (2011). Retrieved on June 25, 2014 from: http://www.greenbuildingindex.org/Resources/GBI\%20Tools/

Reap, J. J. (2009). Holistic biomimicry: A biologically inspired approach to environmentally benign engineering. (Doctoral dissertation) Georgia Institute of Technology, Ann Arbor.

Yeang, K., (2006). Ecodesign: a manual for ecological design. London: Wiley-Academy.

Zanowick, M. B. (2011). Biomimicry: Nature's Time-Tested Framework for Sustainability. Retrieved from peakstoprairies.org/library/.../2012.../ Biomimicry_overview_01_12.doc

Zari, M. (2015). Mimicking ecosystems for bio-inspired intelligent urban built environments. Intelligent Buildings International, 8(2), 57-77.

Zari, M. \& Storey, J.B. (2007). An ecosystem based biomimetic theory for a regenerative built environment. In Proceedings of SB07: Sustainable Construction, Materials and Practices: Challenge of the Industry for the New Millennium. Lisbon, Portugal. 